\title{
Low anterior resection syndrome score among Nepalese population undergoing lower anterior resection for rectal
} carcinoma

\author{
Maharjan DK' ${ }^{1}$ Acharya SC ${ }^{2}$, Thapa $\mathrm{PB}^{3}$
}

'Dhiresh Kumar Maharjan, Lecturer, Department of Surgery, Kathmandu Medical College Teaching Hospital, ${ }^{2}$ Sandhya Chapagain Acharya, Associate Professor, Department of Clinical Oncology, National Academy Medical Sciences, Bir Hospital, ${ }^{3}$ Prabin Bikram Thapa, Professor, Department of Surgery, Kathmandu Medical College Teaching Hospital

\begin{abstract}
Background: With more sphincters preserving surgery being performed for distal rectal cancer, these have been associated with clusters of symptoms experienced by the patient after reversal of diverting ileostomy collectively known as low anterior resection syndrome.

Objective: Our objective is to know incidence of Lower Anterior Resection (LAR) syndrome in different phase of time in our context using low anterior resection symptom score translate in Nepali language.

Methodology: This is an observational descriptive study conducted at Department of Surgery, Kathmandu Medical College and Department of Clinical Oncology, Bir Hospital, Kathmandu from Jan 2015 till Jan 2017. All patients who had undergone low and ultra low anterior resection for middle and low rectal cancer respectively after a long course of neoadjuvant concurrent chemo radiotherapy, having undergone a reversal of diverting ileostomy after 6 weeks of primary surgery were included. A Nepalese version of low anterior resection score was developed after translation from English and scoring was done on $30^{\text {th }}$ day, at the end of 6 months and 1 year postoperative following reversal of ileostomy. Results: Out of 43 consecutive patient $100 \%$ of patients had features of major low anterior resection syndrome during 30 days of ileostomy reversal. However, $46.5 \%$ patient showed major low anterior resectionsyndrome during 6 months of follow up and that decreased to $34.9 \%$ showed major LAR syndrome upon one year of follow up.

Conclusions: The Low anterior resection syndrome score converted in Nepali language is feasible to use and helps in comparing the functional results of reconstruction after low or ultralow anterior resection and our study have shown improvement in score with time.
\end{abstract}

Key words: Rectal cancer; LAR syndrome; QOL

\section{INTRODUCTION}

$\mathrm{R}$ ectal cancer treatment have seen paradigm shift in last $21^{\text {st }}$ century with improvement in surgical approach anduse of neoadjuvant chemo radiotherapy. These days, more sphincter preserving surgery is being performed for distal rectal cancer than sphincter sacrificing surgery such as abdominal perineal resection with permanent stoma. However, sphincter preservation have been associated with clusters of symptoms

Address for correspondence

Dr. Dhiresh Kumar Maharjan

Lecturer

Department of Surgery

Kathmandu Medical College Teaching Hospital

Sinamangal, Kathmandu

E-mail: maharjandhiresh@gmail.com experienced by patients postoperatively usually after reversal of diverting ileostomy, which are collectively known as low anterior resection (LAR) syndrome.

Emmertsen $\mathrm{KJ}^{\prime}$ first propagated the LAR symptom score and has been validated throughout the world in various international languages ${ }^{2-4}$. The use of LAR symptom score have been able to objectify the patient postsurgery difficulties and are related with quality of life in terms ofthe European Organization for Research and Treatment of Cancer (EORTC) QLQ-C305. We have been able to translate the questions in Nepali language and have tried to see the use of it in Nepalese context.

Our objective is to know incidence of LAR syndrome in our context and evaluate its significance with time duration. 


\section{METHODOLOGY}

This is an observational descriptive study conducted at Department of Surgery, Kathmandu Medical College and Teaching Hospital and Department of Clinical Oncology,National Academy of Medical Sciences, Bir Hospital, Kathmandu, Nepal from Jan 2015 till Jan 2017.

Inclusion criteria: All patients who had undergone low and ultra low anterior resection for middle and low rectal cancer respectively after long course of neoadjuvant concurrent chemo radiotherapy of $50 \mathrm{~Gy}$ in 28 fractions to the pelvis for five and half weeks and concurrent capcitabine $825 \mathrm{mg} / \mathrm{m} 2$ twice daily 5 days a week for a period of five and half weeks and surgery was done after 4-6 weeks ${ }^{6-8}$. They underwent reversal of diverting ileostomy after 6 weeks. Patients related variables includes age, gender, distance from anal verge(more than $5 \mathrm{~cm}$ or less than $5 \mathrm{~cm}$ ), long course neoadjuvant chemo radiotherapy (received or not), type of surgery (low anterior resection or ultralow anterior resection), pathological Tumor Node and Metastasis (TNM) classification, the grading of mesorectal excision (complete, near complete or non complete), the surgical approach used (open, laparoscopic assisted, total laparoscopic), type of anastomosis (colorectal or coloanal; manual or mechanical), the creation of a diverting stoma (yes or no), postoperative complication of the anastomosis (dehiscence or abscess, yes or no), reversal of ileostomy (done or not), follow up after ileostomy reversal 30 days, 6 months and 1 year.

Exclusion criteria: Low Rectal cancer who underwent Abdominal Perineal Resection (APR) and those in whom, there is failure to revert diverting ileostomy.

Nepalese version of LAR score was developed after translation from English version (annex1) shows the LARS questionnaire, which is composed of 5 questions concerning the following: incontinence for flatus, incontinence for liquid stool, frequency of bowel movements, clustering of stools, and urgency, the sum of all the items varies from 0 to 42 points, for classification into 3 groups: non-LARS (0-20 points), minor LARS (2129 points) and major LARS (30-42 points).

First LAR scoring questionnaire on $30^{\text {th }}$ post operative day was done at department of clinical oncology by second author as patient go for adjuvant chemoradiotherapy.

Second LAR scoring questionnaire on 6 months post operative day was done at department of surgery by first and third author.
Third LAR scoring questionnaire on 1 year after surgery was done at department of surgery by first and third author.

All the information was collected during the follow up visit by the patients at the scheduled date.

Ethical approval was taken from Institutional Review Committee, Kathmandu Medical College Teaching Hospital (KMCTH) before commencing study and proper informed consent was taken from patient.

As per KMCTH departmental surgical malignancy audit 2012, there were 15 cases of carcinoma rectum thathad undergone surgery at the Department of Surgery. Hence, we expect a minimum of 10 cases of carcinomaof rectum per year. Statistical Package for Social Sciences (SPSS) version 16 was used. Descriptive variables were mentioned as frequency and represented in percentage and averages with standard deviation for continuous variables.

\section{RESULTS}

From Jan 2015 till Jan 2017, total 48 patients with locally advanced mid and lower rectal cancer underwent long course neoadjuvant concurrent chemoradiotherapy of $50 \mathrm{~Gy}$ in 28 fractions to the pelvis for five and half weeks and concurrent capcitabine $825 \mathrm{mg} / \mathrm{m} 2$ twice daily 5 days a week for a period of five and half weeks and surgery was done after 4-6 weeks. Among them 27patients with mid rectum underwent low anterior resection while 18 patients with lower rectal cancer underwent ultralow anterior resection and 3 patients underwent APR.

We included 43 patients during study and excluded 3 patients who underwent APR,one patient who underwent low anterior resection had radiation induced anastomotic stricture leading to permanent diverting ileostomy hence excluded and one who had ultralow anterior resection lost follow up after ileostomy reversal.

The median age of the study population $(\mathrm{N}=43)$ was 55 years. The male and female population was nearly equal. The distance from anal verge in almost three fifth participants was $\geq 5 \mathrm{~cm}$. Thirteen participants (30.2\%) underwent open surgery and remaining was either total laparoscopic or laparoscopic assisted. (Table 1).

Out of 43 consecutive patient $100 \%$ of patient had features of major LAR syndrome during 30 days of ileostomy reversal. However, $46.5 \%$ patient showed major LAR syndrome during 6 months of follow up and that decreased to $34.9 \%$ showed major LAR syndrome upon 1 year of follow up (Table 1). 


\section{DISCUSSION}

Despite improvement in surgical technique in terms of mesorectal excision or use of laparoscopy for better anatomical view and less tissue trauma, use of neoadjuvant radiotherapy and use of anastomotic staplers, anatomical restoration of rectal continuity still holds constellation of defecatory symptoms as LAR syndrome. Our study is the first of this kind providing information about incidence of LAR syndrome in Nepalese population and how they affect patient quality of life.

LAR syndrome have been attributed as multifactorial causation from loss of rectal reservoir after surgical resection ${ }^{9,10}$ autonomic denervation ${ }^{11}$, pelvic radiotherapy ${ }^{12,13}$, increase in colonic motility ${ }^{14}$, reduction in anal resting pressure probably due to sphincter injury during application of staplers ${ }^{15}$.Though many factors have been proposed for causation of LAR syndrome,type of surgery according to height of tumor from anal verge (low anterior or ultralow anterior resection) and use of preoperative radiotherapy have been associated with poor functional outcome after $\operatorname{LAR}^{16,17}$. In our study, in first follow up period at $30^{\text {th }}$ day post reversal of ileostomy all patients (100\%) have major LAR symptoms. However, in $2^{\text {nd }}$ follow up period 6 months after ileostomy reversal there were decrease from major to minor in almost half of the patient (10) among those who went low anterior resection $(n=26)$ whereas 13 patient had minor symptoms among ultralow anterior resection $(n=17)$. With further increase in time duration at $3^{\text {rd }}$ follow up period at one year after ileostomy reversal, our study shows further improvement in LAR symptoms from minor to nil among four patient each among both groups (LAR and ultralow AR group) respectively. However, majority of patient still have some form of symptoms persisted either minor or major symptoms probably as our entire patient had preoperative concurrent long course chemoradiotherapy.

Table 1: Demographic, clinical and therapeutic characteristics of study population

\begin{tabular}{|c|c|}
\hline Study Variables & Number (Percentage) \\
\hline Median Age (Minimum-Maximum) & 55 years $(15-85)$ \\
\hline \multicolumn{2}{|l|}{ Gender $(\mathrm{N}=43)$} \\
\hline Male & $21(48.8)$ \\
\hline Female & $22(51.2)$ \\
\hline \multicolumn{2}{|l|}{ Distance from Anal Verge( $N=43)$} \\
\hline$<5 \mathrm{~cm}$ & $17(39.5)$ \\
\hline$\geq 5 \mathrm{~cm}$ & $26(60.5)$ \\
\hline \multicolumn{2}{|l|}{ Type of Surgery $(\mathrm{N}=43)$} \\
\hline Low Anterior Resection(LAR) & $26(60.5)$ \\
\hline Ultra LAR & $17(39.5)$ \\
\hline \multicolumn{2}{|l|}{ Surgical Approach ( $N=43)$} \\
\hline Open Surgery & $13(30.2)$ \\
\hline Laparoscopic Assisted & $27(62.8)$ \\
\hline Total Laparoscopic & $3(7.0)$ \\
\hline \multicolumn{2}{|l|}{ Type of Anastomosis ( $N=43)$} \\
\hline Hand Sewn & $30(69.8)$ \\
\hline Stapled Anastomosis & $13(30.2)$ \\
\hline \multicolumn{2}{|c|}{ Grading of Macroscopic Specimen ( $N=43$ ) } \\
\hline Complete & $33(76.7)$ \\
\hline Near Complete & $10(23.3)$ \\
\hline \multicolumn{2}{|l|}{ LAR Score in 30 Days $(\mathrm{N}=43)$} \\
\hline Major & $43(100 \%)$ \\
\hline \multicolumn{2}{|l|}{ LAR Score in 6 months $(\mathrm{N}=43)$} \\
\hline Minor & $23(53.5 \%)$ \\
\hline Major & $20(46.5 \%)$ \\
\hline \multicolumn{2}{|l|}{ LAR Score in 1 year $(\mathrm{N}=43)$} \\
\hline No LARS & $8(18.6)$ \\
\hline Minor LARS & $20(46.5)$ \\
\hline Major LARS & 15 (34.9) \\
\hline
\end{tabular}




\section{Table 2: Relation between LARS and study variables}

\begin{tabular}{|c|c|c|c|c|c|}
\hline \multirow[t]{3}{*}{ Study Variables } & \multicolumn{5}{|c|}{ LARS Category } \\
\hline & \multicolumn{2}{|c|}{ At 6 months } & \multicolumn{3}{|c|}{ At 1 year } \\
\hline & Minor & Major & No & Minor & Major \\
\hline \multicolumn{6}{|l|}{ Age Group (Years) } \\
\hline$\leq 40$ & 5 & 6 & 0 & 7 & 4 \\
\hline $41-50$ & 5 & 3 & 3 & 3 & 2 \\
\hline $51-60$ & 4 & 2 & 2 & 2 & 2 \\
\hline $61-70$ & 3 & 2 & 2 & 2 & 1 \\
\hline$>70$ & 6 & 7 & 1 & 6 & 6 \\
\hline \multicolumn{6}{|l|}{ Gender $(\mathrm{N}=43)$} \\
\hline Male & 10 & 11 & 4 & 8 & 9 \\
\hline Female & 13 & 9 & 4 & 12 & 6 \\
\hline \multicolumn{6}{|c|}{ Distance from Anal Verge ( $N=43)$} \\
\hline$<5 \mathrm{~cm}$ & 13 & 4 & 4 & 10 & 3 \\
\hline$\geq 5 \mathrm{~cm}$ & 10 & 16 & 4 & 10 & 12 \\
\hline \multicolumn{6}{|l|}{ Type of Surgery $(\mathrm{N}=43)$} \\
\hline Low Anterior Resection(LAR) & 10 & 16 & 4 & 10 & 12 \\
\hline Ultra LAR & 13 & 4 & 4 & 10 & 3 \\
\hline \multicolumn{6}{|l|}{ Surgical Approach ( $N=43)$} \\
\hline Open Surgery & 2 & 11 & 0 & 5 & 8 \\
\hline Laparoscopic Assisted & 19 & 8 & 8 & 13 & 6 \\
\hline Total Laparoscopic & 2 & 1 & 0 & 2 & 1 \\
\hline \multicolumn{6}{|l|}{ Type of Anastomosis ( $N=43)$} \\
\hline Hand Sewn & 19 & 11 & 7 & 16 & 7 \\
\hline Stapled Anastomosis & 4 & 9 & 1 & 4 & 8 \\
\hline \multicolumn{6}{|c|}{ Grading of Macroscopic Specimen ( $N=43)$} \\
\hline Complete & 18 & 15 & 6 & 16 & 11 \\
\hline Near Complete & 5 & 5 & 2 & 4 & 4 \\
\hline
\end{tabular}

Another important finding of our study is may be use of laparoscopic approach to surgery have significant impact in decreasing the LAR symptoms as there has been decrease to minor symptoms in 19 patient in $2^{\text {nd }}$ follow up period which further improved to nil symptoms in 8 patient after one year. This could be attributed to magnifying advantage of laparoscopic approach while tissue handling. However major symptoms during first follow up period $\left(30^{\text {th }}\right.$ post ileostomy reversal) could be due to tissue edema around autonomic nerve plexus.

Another striking feature we have noticed is that hand sewn anastomosis with absorbable suture have shown decrease in symptoms score from minor among 19 patient in $2^{\text {nd }}$ follow up period to 7 patient in $3^{\text {rd }}$ follow up.This feature was different from use of staplers for anastomosis as it shows very less change in symptoms. This finding contradicts with finding according to Laurent $A$ et al who have shown that stapled pouch anastomosis resulted in less urgency (5\% vs. $37 \%$ ) than a hand sewn anastomosis ${ }^{18}$.

As we routinely performed end to end anastomosis either hand sewn with suture or with staplers with all having diverting protective ileostomy, we were not able to compare different types of anastomosis techniques and its impact on defecatory symptoms.

Though, the small number of study size has been our limitations of this study, however, patient kept on follow up at specific point of time during scoring questionnaire which we think helps to reduce the remember biasness had it been taken after one year.

\section{CONCLUSION}

The Low anterior resection syndrome score converted in Nepali language is feasible to use and helps to compare the functional results of reconstruction after low or ultra-low anterior resection and our study have shown improvement in LAR score as time passes on. 


\section{REFERENCES}

1. Emmertsen $\mathrm{KJ}$, LaurbergS.Low anterior resection syndrome score: development and validation of a symptom-based scoring system for bowel dysfunction after low anterior resection for rectal cancer. Ann Surg. 2012 May; 255(5):922-8. [ PubMed]

2. Ekkarat $\mathrm{P}$, Boonpipattanapong $\mathrm{T}$, Tantiphlachiva $\mathrm{K}$, Sangkhathat $\mathrm{S}$. Factors determining low anterior resection syndrome after rectal cancer resection: A study in Thai patients. Asian J Surg. 2016 Oct; 39(4):225-31.[ DOI ]

3. Juul $T$, Battersby $N J$, Christensen $P$, Janjua AZ, Branagan G, Laurberg $S$ et al. UK LARS Study Group. Validation of the English translation of the low anterior resection syndrome score. Colorectal Dis. 2015 Oct; 17(10):908-16.[ DOI ]

4. Hou XT, Pang D, Lu Q, Yang $P$, Jin SL, Zhou YJ etal. Validation of the Chinese version of the low anterior resection syndrome score for measuring bowel dysfunction after sphincter-preserving surgery among rectal cancer patients. Eur J Oncol Nurs. 2015 Oct; 19(5):495-501. [ PubMed ]

5. Aaronson NK, Ahmedzai S, Bergman B, Bullinger M, Cull A, Duez NJ, Filiberti A, Flechtner H, Fleishman $\mathrm{SB}$, de Haes JC, et al.The European Organization for Research and Treatment of Cancer QLQ-C30: a quality-of-life instrument for use in international clinical trials in oncology. J Natl Cancer Inst. 1993 Mar 3; 85(5):365-76.[ PubMed ]

6. Allegra CJ, Yothers G, O'Connell MJ, Beart RW, Wozniak TF, Pitot HC, et al. Neoadjuvant 5-FU or Capecitabine plus radiation with or without oxaliplatin in rectal cancer patients: a phase III randomized clinical trial. J Natl Cancer Inst. 2015; 107(11):djv248. [ PubMed]

7. Buzatti Kelly Cristine de Lacerda Rodrigues, Petroianu Andy. Pathophysiological aspects of the low anterior resection syndrome for treatment of rectal cancer. Rev. Col. Bras. Cir. [Internet]. 2017 Aug [cited 2018 July 28] ; 44( 4 ): 397-402. [ Full Text ]

8. Gay HA, Barthold HJ, O'Meara E, Bosch WR, El Naqal, Al-Lozi $R$, et al. Pelvic normal tissue contouring guidelines for radiation therapy: a Radiation Therapy Oncology Group consensus panel atlas. Int J Radiat Oncol Biol Phys. 2012; 83(3):e353-62.[ DOI ]

9. Heriot $A G$, Tekkis PP, Constantinides V, Paraskevas
P, Nicholls RJ, Darzi A, et al. Meta-analysis of colonic reservoirs versus straight coloanal anastomosis after anterior resection. Br J Surg. 2006;93(1):19-32. [PubMed ]

10. Rubin F, Douard R, Wind P. The functional outcomes of coloanal and low colorectal anastomoses with reservoirs after low rectal cancer resections. Am Surg. 2014;80(12):1222-9. [ PubMed ]

11. Lee WY, Takahashi T, Pappas T, Mantyh CR, Ludwig KA. Surgical autonomic denervation results in altered colonic motility: an explanation for low anterior resection syndrome? Surgery. 2008;143(6):778-83. [ PubMed ]

12. Bregendahl S, Emmertsen KJ, Lous J, Laurberg S. Bowel dysfunction after low anterior resection with and without neoadjuvant therapy for rectal cancer: a population-based cross-sectional study. Colorectal Dis. 2013; 15(9):1130-9. [ PubMed ]

13. Lundby L, Krogh K, Jensen VJ, Gandrup P, Qvist N, Overgaard J, et al. Long-term anorectal dysfunction after postoperative radiotherapy for rectal cancer. Dis Colon Rectum. 2005; 48(7):1343-9. [ PubMed ]

14. Reibetanz J, Kim M, Germer CT, Schlegel N. [Late complications and functional disorders after rectal resection: prevention, detection and therapy]. Chirurg. 2015;86(4):326-31. [ DOI ]

15. Ho YH, Tsang C, Tang CL, Nyam D, Eu KW, SeowChoen F. Anal sphincter injuries from stapling instruments introduced transanally: randomized, controlled study with endoanal ultrasound and anorectal manometry. Dis Colon Rectum. 2000;43(2):169-73. [ PubMed ]

16. Battersby N, Bouliotis G, Emmertsen K, Laurberg $\mathrm{S}$, Moran B. An externally validated nomogram to predict the risk of bowel dysfunction following an anterior resection. Gut. 2015; 64: A48.[ PubMed ]

17. Bondeven P, Emmertsen KJ, Laurberg S, Pedersen BG. Neoadjuvant therapy abolishes the functional benefits of a larger rectal remnant, as measured by magnetic resonance imaging after restorative rectal cancer surgery. Eur J Surg Oncol. 2015; 41: 1493-39. [PubMed ]

18. Laurent A, Parc Y, McNamara D, Parc R, Tiret E. Colonic J-pouch-anal anastomosis for rectal cancer: a prospective, randomized study comparing handsewn vs. stapled anastomosis. Dis Colon Rectum. 2005; 48: 729-34.[ PubMed ]. 